\title{
Inter-cohort growth for three tropical resources: tilapia, octopus and lobster
}

\author{
Iván Velázquez-Abunader ${ }^{1 *}$, Victor Manuel Gómez-Muñoz ${ }^{2}$, Silvia Salas ${ }^{1}$
}

\& Javier M. J. Ruiz-Velazco ${ }^{3}$

1. Centro de Investigación y de Estudios Avanzados del Instituto Politécnico Nacional, Unidad Mérida. Mérida Yucatán, México. Km 6 Antigua carretera a Progreso, Mérida Yucatán, México; jvelazquez@mda.cinvestav.mx, ssalas@mda.cinvestav.mx

2. Centro Interdisciplinario de Ciencias Marinas del Instituto Politécnico Nacional, La Paz, Baja California Sur, México. Apdo. Postal 592, La Paz, B.C.S. 23000, México; vgomez@ipn.mx

3. Escuela Nacional de Ingeniería Pesquera, Universidad Autónoma de Nayarit, San Blas, Nayarit, México. Km 12 Bahía de Matanchén, Mpio. de San Blas, Nayarit, México; marcialj@uan.edu.mx

* Correspondence

Received 08-X-2014. Corrected 18-III-2015. Accepted 20-IV-2015.

\begin{abstract}
Growth parameters are an important component for the stock assessment of exploited aquatic species. However, it is often difficult to apply direct methods to estimate growth and to analyse the differences between males and females, particularly in tropical areas. The objective of this study was to analyse the inter-cohort growth of three tropical resources and discuss the possible fisheries management implications. A simple method was used to compare individual growth curves obtained from length frequency distribution analysis, illustrated by case studies of three tropical species from different aquatic environments: tilapia (Oreochromis aureus), red octopus (Octopus maya) and the Caribbean spiny lobster (Panulirus argus). The analysis undertaken compared the size distribution of males and females of a given cohort through modal progression analysis. The technique used proved to be useful for highlighting the differences in growth between females and males of a specific cohort. The potential effect of extrinsic and intrinsic factors on the organism's development as reflected in the size distribution of the cohorts is discussed. Rev. Biol. Trop. 63 (3): 617-627. Epub 2015 September 01.
\end{abstract}

Key words: modal progression, growth, sex, lobster, octopus, tilapia.

Growth studies for stock assessment usually require estimations of catchability, recruitment, and virtual population analysis, among other elements (Haddon, 2001; Froese \& Binohlan, 2003). Several authors have noted that the growth rate and maximum length that can be reached by individuals may vary depending on the environment, latitude, time, species and sex (Bacha \& Amara, 2012; Ohlberger et al., 2013; Flores, Licandeo, Cubillos, \& Mora, 2014). In addition, growth can increase or decrease according to biological processes such as reproduction, including maturity and spawning (Lester, Shuter \& Abrams, 2004) as well as moulting periods in the case of crustaceans
(Zetina-Moguel \& Ríos-Lara, 2000). These changes in growth may be due to the amount of energy invested in certain biological processes during the different stages of the organism's life history (Day \& Taylor, 1997), in such a way that females and males of the same species and population, may present different growth patterns for different cohorts, and individual variability could generate biases in population parameter estimates (Cerviño, 2013).

The stock assessment models applied to exploited populations commonly rely on population growth parameters of the von Bertalanffy growth function (vBGF) (von Bertalanffy, 1938) and there are currently two methods 
used to estimate these parameters: size distribution analysis and analysis of growth rings in hard structures.

The method based on size distribution calculates the vBGF parameters indirectly by modal progression analysis, which is based on size frequency distribution and assumes that: a) the organism size of each cohort is pooled within a modal group, b) that the largest organisms are the oldest, and c) that each modal group can be followed over time. This method has been widely used for tropical species (Munro \& Pauly, 1983). This offers an accessible and practical option to researchers from countries with limited economic or technical capabilities, which generally collect data on size of exploited populations for their fisheries assessment (Chuenpagdee, Salas, Charles, $\&$ Seijo, 2011). Estimates of the vBGF equation parameters using this method have been made with the help of different computational routines such as: Electronic Length Frequency Analysis, Shepherd's Length Composition Analysis, Projection Matrix Method; MULTIFAN (Fournier, Sibert, Majkowski, \& Hampton, 1990) or by empirical equations (Froese \& Binohlan, 2003).

The direct method consists of a non-linear regression analysis based on size and age data, where age is calculated by counting growth lines in hard structures such as scales, otoliths, spines or vertebrae (Maci \& Basset, 2009). This method has commonly been used for species in temperate regions where the intraannual variations in the environment favour the record of these marks (Marco-Ruis, Caballero, Morán, \& García-de Leaniz, 2013).

The indirect methods have commonly been used in data-poor circumstances (Ohlberger et al., 2013). In this context, a precautionary approach is applied, in which researchers need to be creative in order to efficiently use these data to make appropriate management decisions rather than avoid facing fisheries problems (Deriso, Quinn II, \& Neal, 1985; Maunder \& Punt, 2013). Even though current literature recommends the use of direct methods to obtain growth parameters and trends, the indirect methods continue to be applied to several species worldwide. Such is the case with some cephalopod (Keyl, Argüelles, \& Tafur, 2011; López-Rocha et al., 2012), mollusc (Huang \& Hseu, 2010) and fish species (Ohlberger et al., 2013; Sossoukpe, Nunoo, Ofori-Danson, Fiogbe, \& Dankwa, 2013), to fulfil the high demand for management measures and control of these fisheries.

Stock assessment has been carried out using surplus production models (Schaefer, 1954) and age-structure models, such as those proposed by Beverton and Holt (1957). The former mainly includes analysis of species from temperate environments and requires long time series information; while the latter, requires information about population dynamics, including growth estimates by age-cohort. In some areas, studies of this nature have been limited because of the difficulty of aging species, especially in tropical environments or due to the lack of long time-series data (Sossoukpe et al., 2013). Furthermore, the environmental conditions of the species' habitat can have an impact on the cohort trends and hence on the estimates of population dynamics and stock assessment. Under these particular conditions a comparison is made of different growth models, fitted to a particular species (Pawlak \& Hanumara, 1991; Haddon, 2001). Francis (1996) used six different methods to compare growth curves in two fish species and indicated that comparing growth rates where sizes approach $L_{\infty}$ can be practical, since the species that approach their $L_{\infty}$ earlier can be said to grow faster. Wang and Milton (2000) followed the analyses performed by Francis (1996) emphasizing the comparison of growth curves between species and areas, but did not offer an alternative statistical technique when only size data are available. There are also several useful methods for growth curve comparison by sex (Kimura, 1980; Bernard, 1981; Chen, Jackson, \& Harvey, 1992) but despite their usefulness in certain cases, these statistical techniques are not suitable for comparing the size distribution curves of animals of different sexes. 
Differential growth patterns between aquatic organisms of different sexes can also influence on population dynamics and stock assessment, particularly in cases where fishing incidence is higher for one of the class groups (Sasikumar, Mohamed, \& Bhat, 2013). This is the case of the red octopus Octopus maya (Voss \& Solís-Ramírez, 1966), where females show parental care to their young. During this time, they do not take the bait and are therefore less vulnerable to fishing gears; hence, a higher incidence of males at several stages is evident (Arreguín-Sánchez, 2000; Salas, Cabrera, Palomo, \& Torres-Irineo, 2009). Therefore these patterns need to be understood in order to interpret the above conditions.

According to Sainsbury (1980), the lack of consideration of individual variation and asymmetries in size distribution of exploited populations, could lead to the rejection of the von Bertalanffy model in cases where it is used for growth analysis. In the present study, the Kolmogorov-Smirnov (K-S) statistic, built through modal progression analysis, proved to be simple and useful tool to compare the size distribution of aquatic individuals that live in different environments. This helped to identify inter-cohort differences and hence to understand growth patterns of animals that face different environmental conditions or cohort differences within the same population.

\section{MATERIAL AND METHODS}

Three species from different habitats and with distinct habits were considered as cases studies for this analysis. We used growth parameters estimated by Peña-Messina, TapiaVarela, Velázquez-Abunader, Orbe-Mendoza and Ruiz-Velazco Arce, (2010) from standard lengths (SL) of a total of 2412 individuals (1371 males and 1041 females) of tilapia Oreochromis aureus (Steindachner, 1864), sampled from June 2000 to July 2001 in a tropical reservoir in Mexico. In addition, mantle lengths (ML) for a total of 5723 specimens (3021 males and 2702 females) of the red octopus Octopus maya, were sampled from
August to December 2009 along the coasts of Yucatan, Mexico (Voss \& Solís-Ramírez, 1966). In addition a total of 6642 individuals (3413 males and 3229 females) of the Caribbean lobster Panulirus argus (Latreille, 1804) were sampled from August 2005 to February 2006 from the coasts of Yucatan, Mexico. In the case of the Caribbean spiny lobster, size data were transformed from abdominal length (AL) to cephalothorax length (CL) using an empirical equation proposed by Cruz (2002) for this species, so that the results were comparable with other studies.

The estimates were made using the vBGF growth function as a base, and the calculations were carried out with the ELEFAN-I package (included into FISAT II software), which estimates $k$ and $L_{\infty}$ parameters (Gayanilo, Sparre, \& Pauly, 1996).

The $t_{0}$ parameter was estimated using an empirical function (Pauly, 1979):

$\log _{10}\left(t_{0, s}\right)=-0.3922-0.2752 \log _{10}\left(L_{\infty, s}\right)-1.038 \log _{10}\left(k_{s}\right)$

Although equation 1 was originally proposed for fish species (Pauly, 1979), it has also been used for other species including molluscs (Wright-López, Holguín-Quiñones, ArreguínSánchez, \& Roque-Villada, 2009) and crustaceans (Castillo, Eslava, \& González, 2011).

The relative age of each individual was obtained by solving the classical vBGF model (von Bertalanffy, 1938) to:

$$
t_{s}=t_{0, s}-\left[\frac{1}{k_{s}} \ln \left(1-\frac{L_{t, s}}{L_{\infty, s}}\right)\right]
$$

where $t$ is the relative age of individuals from gender $s, t_{0}$ is the relative age when length is equal to $0, k$ is the growth coefficient, $L_{t}$ is the length at time $t$, and $L_{\infty}$ is the asymptotic length from the growth curve.

The sizes for each sex $s$ were grouped by cohorts, using $\mathrm{A}+$ to indicate the organisms of 
cohort A that had not yet reached cohort A +1 , starting with group $0+$ (organisms younger than cohort 1), $1+$ (organisms younger than cohort 2), and so on, up to the final group $t_{s f}+$ where the sample size of both groups, according to its gender (sex) was considered appropriate, in order to compare the size distributions of each cohort. The literature reports differences between males and females in lobster (Cabrera $\&$ Salas, 2011) and octopus (Boyle \& Rodhouse, 2005); in the case of tilapia, different comparisons have shown that the males grow larger than the females (Beltrán-Álvarez, Sánchez-Palacios, Valdez, \& Ortega-Salas, 2010).

In order to compare inter-cohort differences within the same population given different sexes, the non-parametric Kolmogorov-Smirnov (K-S) statistical test for two independent samples was applied (Torrie, Dickey, \& Steel, 1996) using R software (R Development Core Team, 2013).

\section{RESULTS}

Tilapia: The parameters of the vBGF function for males were: $L_{\infty}=43.21 \mathrm{~cm}$ standard length (SL), $k=0.37 /$ year and $t_{0}=-0.41$ years, whereas for females they were: $L_{\infty}=41.8$ $\mathrm{cm} \mathrm{SL}, k=0.35 /$ year and $t_{0}=-0.43$ years.

Based on the comparative analyses between males and females, no inter-cohort differences were observed at cohort $0+$. In contrast, for cohorts $1+$ and $3+$ significant differences between the sizes of each group were shown $(\mathrm{p}<0.05)$, which indicates that from the first year, growth patterns differ between sexes.

TABLE 1

Kolmogorov Smirnov - test results showing comparisons among size distributions by sex and cohort

\begin{tabular}{|c|c|c|c|c|c|c|c|c|}
\hline \multirow{3}{*}{ Relative age } & \multicolumn{4}{|c|}{ Length $(\mathrm{cm})$} & \multirow{2}{*}{\multicolumn{2}{|c|}{ Kolmogorov Smirnov - test }} & \multirow{2}{*}{\multicolumn{2}{|c|}{$n$}} \\
\hline & \multicolumn{2}{|c|}{ Males } & \multicolumn{2}{|c|}{ Females } & & & & \\
\hline & Min & Max & Min & $\operatorname{Max}$ & $D_{\max }$ & p-level & Males & Females \\
\hline \multicolumn{9}{|c|}{ Oreochromis aureus (SL) } \\
\hline $0+$ & 10.5 & 15.5 & 10 & 17 & 0.26 & $>0.05$ & 19 & 31 \\
\hline $1+$ & 16 & 23.4 & 17.4 & 25.3 & 0.28 & $<0.00001$ & 399 & 1032 \\
\hline $2+$ & 23.5 & 28.9 & 25.4 & 30.5 & 0.59 & $<0.00001$ & 582 & 264 \\
\hline $3+$ & 29 & 32.5 & 31 & 34.6 & 0.68 & $<0.00001$ & 36 & 34 \\
\hline $4+$ & 33 & 37 & 35 & 38 & & Not used in analysis & 5 & 10 \\
\hline \multicolumn{9}{|c|}{ Octopus maya (ML) } \\
\hline $4+$ & 7.7 & 9.3 & 7.4 & 8.6 & 0.57 & $<0.001$ & 28 & 18 \\
\hline $5+$ & 9.4 & 10.7 & 8.7 & 10 & 0.57 & $<0.00001$ & 233 & 110 \\
\hline $6+$ & 10.8 & 12 & 10.1 & 11.2 & 0.68 & $<0.00001$ & 537 & 326 \\
\hline $7+$ & 12.1 & 13 & 11.3 & 12.3 & 0.85 & $<0.00001$ & 584 & 528 \\
\hline $8+$ & 13.3 & 14 & 12.4 & 13.3 & 0.92 & $<0.00001$ & 512 & 484 \\
\hline $9+$ & 14.4 & 15.2 & 13.4 & 14.2 & 1.00 & $<0.00001$ & 384 & 357 \\
\hline $10+$ & 15.3 & 16 & 14.3 & 15 & 1.00 & $<0.00001$ & 298 & 351 \\
\hline $11+$ & 16.1 & 16.7 & 15.1 & 15.7 & 1.00 & $<0.00001$ & 157 & 176 \\
\hline $12+$ & 16.8 & 17.4 & 15.8 & 16.3 & 1.00 & $<0.00001$ & 101 & 125 \\
\hline $13+$ & 17.5 & 17.9 & 16.4 & 16.8 & 1.00 & $<0.00001$ & 63 & 83 \\
\hline $14+$ & 18 & 18.5 & 17 & 17.4 & 1.00 & $<0.00001$ & 74 & 61 \\
\hline $15+$ & 18.7 & 18.8 & 17.5 & 17.8 & & Not used in analysis & 6 & 30 \\
\hline \multicolumn{9}{|c|}{ Panulirus argus (CL) } \\
\hline $1+$ & 5.91 & 7.6 & 6.26 & 8.4 & 0.66 & $<0.00001$ & 252 & 1343 \\
\hline $2+$ & 7.66 & 10.65 & 8.50 & 11.4 & 0.31 & $<0.00001$ & 2175 & 1560 \\
\hline $3+$ & 10.72 & 13 & 11.53 & 13.6 & 0.52 & $<0.00001$ & 558 & 200 \\
\hline $4+$ & 13.06 & 14.82 & 13.65 & 15.1 & 0.41 & $<0.00001$ & 203 & 64 \\
\hline $5+$ & 14.88 & 16.12 & 15.16 & 16.2 & 0.39 & $<0.0001$ & 84 & 37 \\
\hline $6+$ & 16.18 & 17.16 & 16.29 & 16.8 & 0.30 & $>0.05$ & 72 & 17 \\
\hline
\end{tabular}

Min and Max = minimum and maximum lengths. $\boldsymbol{D}=$ maximum distance between the cumulative frequency distributions of the sizes for each sex and relative age of the Kolmogorov test and the probability value of the test. $\boldsymbol{n}=$ number of females and males per relative age, $\mathbf{S L}=$ standard length, $\mathbf{M L}=$ mantle length, $\mathbf{C L}=$ cephalothorax length. 


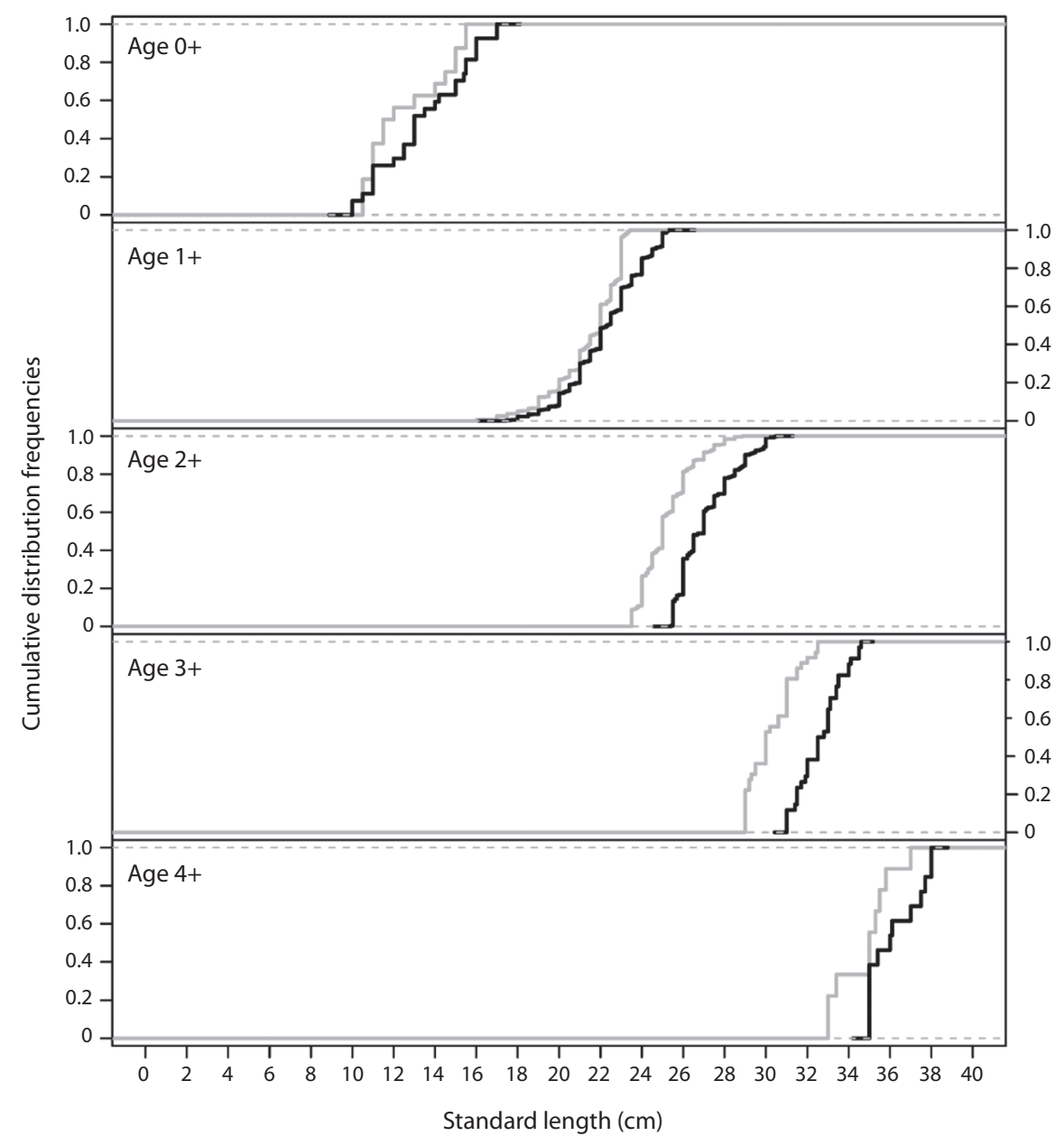

Fig. 1. Cumulative frequencies size distribution by sex and cohort of the blue tilapia (Oreochromis aureus). The grey lines are the cohorts for males and the black lines are the cohorts for females.

The greatest values of maximum distance $(D)$ between the estimated cumulative distributions were for cohorts $2+$ and $3+(\mathrm{p}>0.05)$ (Table 1). Note the overlap of cumulative size distributions at cohort $0+$ in figure 1 . Cohort 4 + was excluded from the analysis because the sample sizes were considered small. The abundance of this resource at later cohorts decreases substantially, possibly due to factors such as natural and fishing mortality (Peña-Messina et al., 2010), causing the catch probability and sample sizes to be low.

Red octopus: The growth parameters derived from this analysis were: $L_{\infty}=22.58$ $\mathrm{cm}$ mantle length (ML), $k=1.2 /$ year and $t_{0}=$ - 0.84 years for males, and $L_{\infty}=21.53 \mathrm{~cm} \mathrm{ML}$, $k=1.1 /$ year and $t_{0}=-0.80$ years for females.

In this species males and females showed significant inter-cohort differences $(\mathrm{p}<0.05)$ for all estimated cohorts; the values of $D$ were always greater than 0.55 and from cohort $9+$ onwards they reached the maximum distances $(D=1.0)$ (Table 1). Cohort $15+$ was excluded from the analysis because of the small sample size. As depicted in figure 2, when cohorts and mantle length increased, the inter-cohort differences were more evident, which indicates that red octopus females and males present differentiated growth for all cohorts considered 


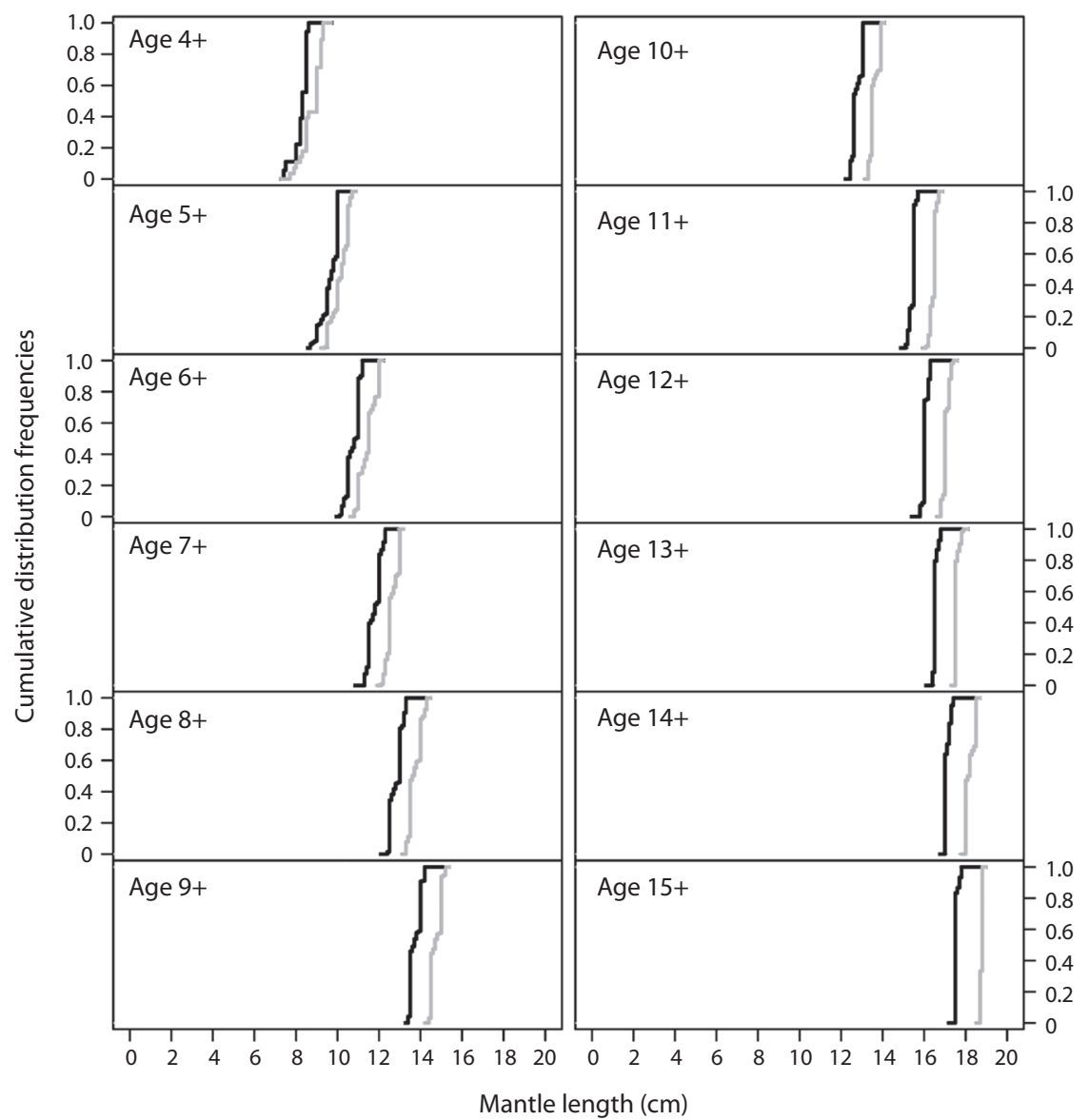

Fig. 2. Cumulative frequencies of size distribution by sex and cohort of the red octopus (Octopus maya). The grey lines are the cohorts for males and the black lines are the cohorts for females.

in the analysis $(>4+)$. The females showed lower growth rates than the males and reached smaller sizes; this pattern agrees with Boyle and Rodhouse (2005), who state that biological processes related to maturity and spawning can generate inter-cohort differences.

Caribbean spiny lobster: The growth parameters estimated for males were $L_{\infty}=$ $20.31 \mathrm{~cm}, k=0.28 /$ year, and for females $t_{0}$ $=-0.17$ years and $L_{\infty}=18.9 \mathrm{~cm}, k=0.34 /$ year and $t_{0}=-0.25$ years.

The K-S test allowed differences between the cohorts to be identified separately for a number of cases, while for others the cohorts overlapped. For instance, the most accelerated growth in females resulted in significant differences between the cohorts of $1+$ to $5+$ in the size distribution of the respective cohort, which indicates sex-differentiated growth and significant inter-cohort differences $(\mathrm{p}<0.05)$. However cohorts of individuals from both sexes overlap after cohort $6+$, which did not show significant differences in individual size regardless of the sex $(p>0.05)$ (Fig. 3, Table 1).

\section{DISCUSSION}

Day and Taylor (1997) and Lester et al. (2004) state the importance of evaluating the growth of organisms through two separate equations: one that uses information on immature 


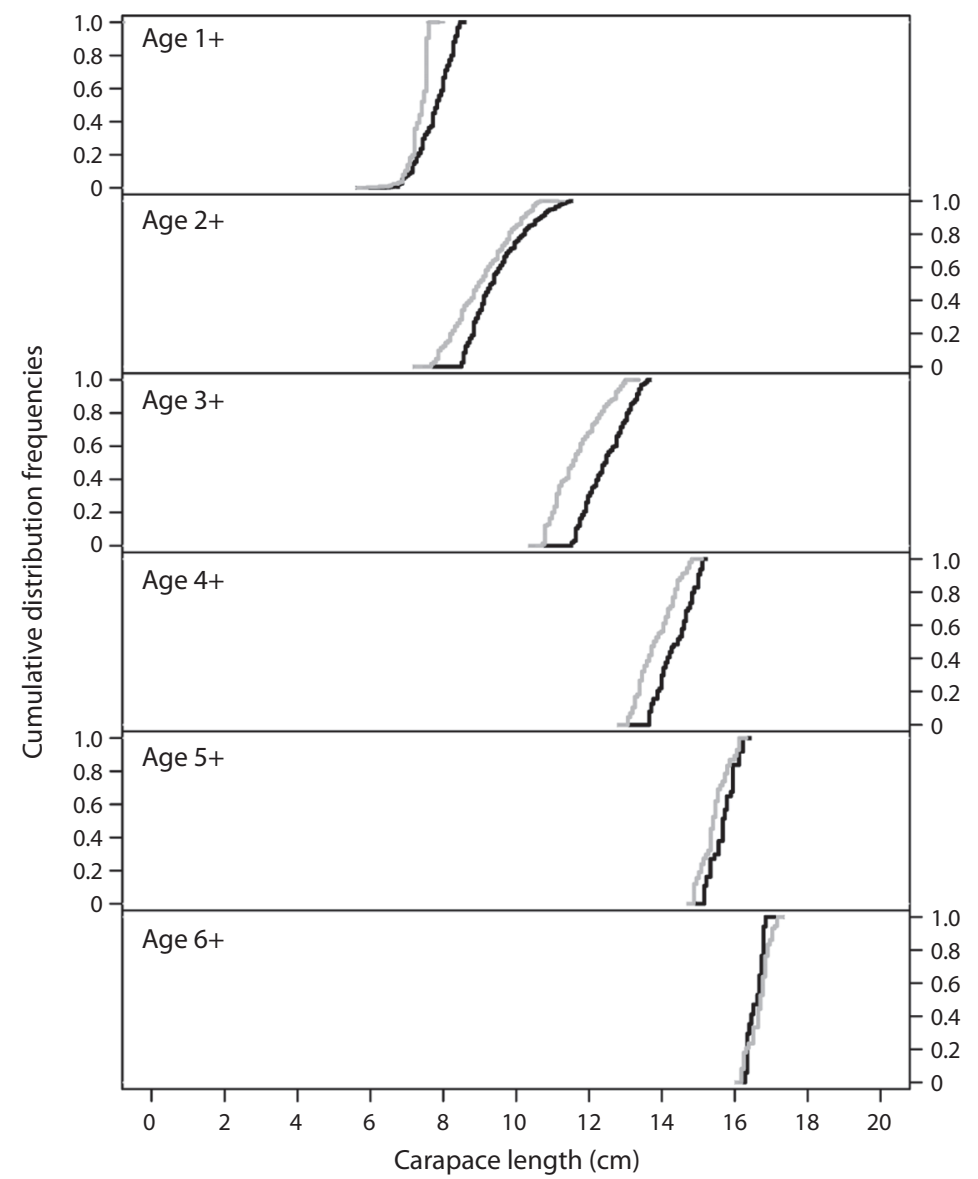

Fig. 3. Cumulative frequencies of size distribution by sex and cohort of the Caribbean spiny lobster (Panulirus argus). The grey lines are the cohorts for males and the black lines are the cohorts for females.

organisms, where their energy input is primarily channelled towards somatic growth, and another equation that considers mature organisms, where energy is mainly invested in reproduction. On this basis, the present study on inter-cohort analysis is relevant as it can help to identify growth differences at the cohort level and hence, changes that exist during the different life stages of the organism. According to Robertson and Butler (2003), the sex differences in growth may be an indicator of the size at which the organisms mature; they state that taxonomically or ecologically similar groups may have different sizes at maturity. The environment can also affect growth processes (Bacha \& Amara, 2012; Whitten, Klaer, Tuck,
\& Day, 2013). Therefore, researchers can use the criterion of a species' first maturity age to separate cohorts by analysis of size frequency distribution information at the respective cohort or to compare cohorts that have their origin in different seasons of the year (Bacha \& Amara, 2012).

The results derived from the analysis of different species in this study made it possible to confirm inter-cohort differences by sex for the case of octopus and lobster, and have been consistent with data reported by various authors including Boyle and Rodhouse (2005) and Wahle and Fogarty (2005), respectively. For example, Wahle and Fogarty (2005) reported that most male lobsters mature 
physiologically at smaller sizes than females; however, the males need to reach the females' sizes by the time they mate. Maturation delays growth and this is more evident in females than males, since they require more energy during the reproductive process; the K-S test was appropriate for differentiating inter-cohort differences between males and females.

Although in the case of tilapia and red octopus there was a clear inter-cohort separation of the oldest individuals, these differences were not statistically significant. One of the reasons for these results could be the sensitivity of the test to small sample sizes (as was the case here); this population segment was subsequently eliminated from the analysis. Goodman (1954) reported that in small sample sizes, estimates of $D$ values behave conservatively. Therefore, it is not convenient to use this method for inter-cohort analysis close to $L_{\infty}$ where the number of individuals that comprise these groups is generally low, particularly if the samples come from commercial catches.

It is important to note that the correct definition of cohorts' interval must be used in order to employ the proposed technique. This must meet two fundamental requirements: (1) the selection of the size interval should define the cohorts as it can have an impact on the analysis; and (2) for each cohort an appropriate sample size needs to be ensured in order to apply the K-S test.

An advantage of inter-cohort analysis through the K-S test is that size data can follow a free statistical distribution given the fact that it is a non-parametric test (Zar, 2010). In addition estimates of relative age from length data from any growth model are not neglected while using this type of analysis. Other techniques, for example the $T^{2}$ statistic, compare the covariance between two sets of parameters of two growth models; however, different combinations of these parameters could lead to similar results in such models. Furthermore this last statistic is applicable to situations where age has been estimated through direct methods and cannot be applied in cases where models were fitted through size frequency distributions.
The method proposed in this study can also be used to compare size frequency distributions when the age has been calculated using direct techniques.

Several authors have studied methods that allow differentiations to be made among growth parameters; a common tool has been the growth index $\Phi$ ' (Haddon, 2001), however, an analysis focused on the identification of inter-cohort differences has been less common.

Munro and Pauly (1983) proposed the $\Phi^{\prime}$ value, based on logarithms of $k$ and $L_{\infty}$ as a tool for contrasting growth patterns between species and areas. The different values of $\Phi^{\prime}$ for several families present a normal distribution and statistical comparisons can be made relatively easily using this method if there are sex-differentiated patterns in growth, although different combinations of $k$ and $L_{\infty}$ can produce results with similar $\Phi^{\prime}$ values (Pauly, 1994; Haddon, 2001). Nonetheless, this estimator does not indicate whether there are differences at specific cohorts for a given species, or if there are differences between different life stages of males and females, expressed in the size distributions and their relative cohorts.

Most techniques allow the whole data distribution to be compared, making it difficult to confirm the inter-sex or inter-cohort differences. The inter-cohort analysis proved to be effective for comparing growth patterns of different species and their sexes; it was possible to provide evidences of the differences between split cohorts at different levels of the growth curves. These differences could be the result of the species' biological processes or the different habitats, which should be taken into account when making decisions concerning the management of these fisheries.

\section{ACKOWLEDGMENTS}

We thank Miguel Cabrera, Gaspar Poot, Enrique Puerto and Edgar Torres for their collaboration in data collection in the field in the case of lobster and octopus. Financial support is acknowledged from CONAPESCA in the case of the lobster and from the National 
Council of Science and Technology (FOMIX) for the octopus case study. We thank the state government in Nayarit, Mexico for partial financial support for the tilapia data collection.

\section{RESUMEN}

Crecimiento inter-cohorte para tres recursos tropicales: tilapia, pulpo y langosta. Los parámetros de crecimiento son un componente importante para la evaluación de las poblaciones de especies acuáticas explotadas. Sin embargo, es complicado aplicar métodos directos para estimar el crecimiento y analizar las diferencias entre machos y hembras particularmente en zonas tropicales. El objetivo de este estudio fue analizar el crecimiento entre cohortes de tres recursos tropicales y discutir las posibles implicaciones en el manejo pesquero. Se utilizó un método simple para comparar las curvas de crecimiento individual obtenidas a través del análisis de distribución de frecuencias de longitudes, para ello se usaron tres casos de estudio de especies tropicales provenientes de diferentes ambientes acuáticos: tilapia (Oreochromis aureus), pulpo rojo (Octopus maya) y la langosta del caribe (Panulirus argus). El análisis consistió en comparar la distribución de longitudes de hembras y machos obtenidas del análisis de progresión modal. Esta técnica puede ser utilizada para resaltar las diferencias en el crecimiento entre hembras y machos de una cohorte específica. En este documento se discute el efecto potencial de los factores intrínsecos y extrínsecos en el desarrollo de los organismos como se refleja en la distribución de tallas de las cohortes.

Palabras clave: progresión modal, crecimiento, sexo, langosta, pulpo, tilapia.

\section{REFERENCES}

Arreguín-Sánchez, F. (2000). Population dynamics and stock assessment for Octopus maya (Cephalopoda: Octopodidae) fishery in the Campeche Bank, Gulf of Mexico. Revista de Biología Tropical, 48, 323-331.

Bacha, M., \& Amara, R. (2012). Inter-cohort differences in growth, condition and feeding of juvenile anchovy (Engraulis encrasicolus) in the Gulf of Béjaia (Algerian coast, SW Mediterranean): Implications for recruitment success. Fisheries Research, 129130, 73-81.

Beltrán-Álvarez, R., Sánchez-Palacios, J., Valdez, G. L., \& Ortega-Salas, A. A. (2010). Edad y crecimiento de la mojarra Oreochromis aureus (Pisces: Cichlidae) en la Presa Sanalona, Sinaloa, México. Revista de Biología Tropical, 58, 325-338.
Bernard, D. R. (1981). Multivariate analysis as a means of comparing growth in fish. Canadian Journal of Fisheries and Aquatic Science, 38, 233-239.

Beverton, R. J. H., \& Holt, S. J. (1957). On the dynamics of exploited fish populations. UK: Springer.

Boyle, P. R., \& Rodhouse, P. (2005). Cephalopods: Ecology and fisheries ( $1^{\text {st }}$ ed.). Oxford: Blackwell.

Cabrera, M. A. \& Salas, S. (2011). Dinámica poblacional y estado de explotación del pulpo Octoups maya del litoral de Yucatán, México. Proceedings of Annual Session of Gulf and Caribbean Fisheries Institute, 64, 100-106.

Castillo, Y., Eslava, N., \& González, L. W. (2011). Crecimiento del cangrejo Callinectes danae (Decapoda: Portunidae) de la Isla Margarita, Venezuela. Revista de Biología Tropical, 59, 1525-1535.

Cerviño, S. (2013). Estimating growth from sex ratio-atlength data in species with sexual size dimorphism. Fisheries Research, 160, 112-119.

Chen, Y., Jackson, D. A., \& Harvey, H. H. (1992). A comparison of von Bertalanffy and polynomial functions in modelling fish growth data. Canadian Journal of Fisheries and Aquatic Science, 49, 1228-1235.

Chuenpagdee, R., Salas, S., Charles, A., \& Seijo, J. C. (2011). Assessing and Managing Coastal Fisheries in Latin America and the Caribbean: Underlying Patterns and Trends. In S. Salas, R. Chuenpagdee, A. Charles, \& J. C. Seijo (Eds.), Coastal Fisheries of Latin America and the Caribbean (pp. 10-25). Rome, Italy: FAO Fisheries Technical Paper.

Cruz, R. (2002). Manual de métodos de muestreo para la evaluación de las poblaciones de langosta espinosa. Roma, Italia: Organización de las Naciones Unidas para la Agricultura y la Alimentación. FAO Fisheries Technical Paper. No. 544. 43pp.

Day, T., \& Taylor, P. D. (1997). Von Bertalanffy's growth equation should not be used to model age and size at maturity. The American Naturalist, 149, 381-393.

Deriso, R. B., Quinn II, T. J., \& Neal, P. R. (1985). Catch-age analysis with auxiliary information. Canadian Journal of Fisheries and Aquatic Science, 42, 815-824.

Flores, L., Licandeo, R., Cubillos, L. A., \& Mora, E. (2014). Intra-specific variability in life-history traits of Anadara tuberculosa (Mollusca: Bivalvia) in the mangrove ecosystem of the Southern coast of Ecuador. Revista de Biología Tropical, 62, 473-482.

Fournier, D. A., Sibert, J. R. Majkowski, J., \& Hampton, J. (1990). MULTIFAN: a likelihood based method for estimating growth parameters and age composition from multiple length frequency data sets illustrated using data for southern bluefin tuna (Thunnus maccoyii). Canadian Journal of Fisheries and Aquatic Science, 47, 301-317. 
Francis, R. I. C. (1996). Do herring grow faster than orange roughy? Fishery Bulletin, 94, 783-786.

Froese, R., \& Binohlan, C. (2003). Simple methods to obtain preliminary growth estimates for fishes. Journal of Applied Ichthyology, 19, 376-379.

Gayanilo, F. C., Sparre, P., \& Pauly, D. (1996). The FAOICLARM Stock Assessment tools (FiSAT) users guide. FAO Computerized information series (Fisheries), 8,300 .

Goodman, L. A. (1954). Kolmogorov-Smirnov tests for psychological research. Psychological Bulletin, 51, 160-168.

Haddon, M. (2001). Modelling and quantitative methods in fisheries. USA: CRC Press.

Huang, W. B., \& Hseu, J. R. (2010). Changes in growth characteristics of the small abalone Haliotis diversicolor (Reeve, 1846) after one decade in a closed culture system: a comparison with wild populations. Fishery Science, 76, 131-137.

Keyl, F., Argüelles, J., \& Tafur, R. (2011). Interannual variability in size structure, age, and growth of jumbo squid (Dosidicus gigas) assessed by modal progression analysis. ICES Journal of Marine Science, 68, 507-518.

Kimura, D. K. (1980). Likelihood methods for the von Bertalanffy growth curve. Fishery Bulletin, 77, 765-776.

Lester, N. P., Shuter, B. J., \& Abrams, P. A. (2004). Interpreting the von Bertalanffy model of somatic growth in fishes: the cost of reproduction. Proceedings of the Royal Society A, 271, 1625-1631.

López-Rocha, J. A., Arellano-Martínez, M., CeballosVázquez, B. P., Velázquez-Abunader, I., CastellanosMartínez, S., \& Torreblanca-Ramírez, E. (2012). Use of length-frequency analysis for growth estimation of the California two-spotted octopus Octopus bimaculatus Verril 1883 of the Gulf of California. Journal of Shellfish Research, 31, 1173-1181.

Maci, S., \& Basset, A. (2009). Spatio-temporal patterns of abundance, size structure and body condition of Atherina boyeri (Pisces: Atherinidae) in a small non-tidal Mediterranean lagoon. Estuarine Coastal and Shelf Science, 87, 125-134.

Marco-Ruis, F., Caballero, P., Morán, P., \& García-de Leaniz, C. (2013). Mixed-Effects Modelling of Scale Growth Profiles Predicts the Occurrence of Early and Late Fish Migrants. Plos One, 8, 1-7.

Maunder, M. N., \& Punt, A. E. (2013). A review of integrated analysis in fisheries stock assessment. Fisheries Research, 142, 61-74.

Munro, J. L., \& Pauly, D. (1983). A simple method for comparing the growth of fishes and invertebrates. Fishbyte, 1, 5-6.
Ohlberger, J. J., Otero, E., Edeline, I. J., Winfield, N. C., Stenseth, C., \& Vollestad, C. (2013). Biotic and abiotic effects on cohort size distributions in fish. Oikos, $122,835-844$.

Pauly, D. (1979). Gill size and temperature as governing factors in fish growth: a generalization of von Bertalanffy's growth formula. Kiel, Germany: Berichte Institut Für Meereskunde, Christian-Albrechts Universität.

Pauly, D. (1994). On the sex of fish and the gender of scientist. A collection of essays in fisheries science. The Netherlands: Springer.

Pawlak, C., \& Hanumara, R. C. (1991). A comparison of non-linear growth models for fisheries. Fisheries Research, 11, 143-154.

Peña-Messina, E., Tapia-Varela, R., Velázquez-Abunader, J. I., Orbe-Mendoza, A. A., \& Ruiz-Velazco Arce, J. M. J. (2010). Growth, mortality and reproduction of the blue tilapia Oreochromis aureus (Perciformes: Cichlidae) in the Aguamilpa Reserovoir, Mexico. Revista de Biología Tropical, 58, 1577-1586.

R Development Core Team. (2013). R: A Language and Environment for Statistical Computing. R Foundation for Statistical Computing, Vienna, Austria, Retrieved from http://www.R-project.org/

Robertson, D. N., \& Butler IV, M. (2003). Growth and size at maturity in the spotted spiny lobster Panulirus guttatus. Journal of Crustacean Biology, 23, 265-272.

Sainsbury, K. J. (1980). Effect of individual variability on the von Bertalanffy growth equations. Canadian Journal of Fisheries and Aquatic Science, 37, 241-247.

Salas, S., Cabrera, M. A., Palomo, L., \& Torres-Irineo, E. (2009). Uso de indicadores para evaluar medidas de regulación en la pesquería del pulpo en Yucatán dada la interacción de flotas. Proceedings of Annual Gulf and Caribbean Fisheries Institute, 61, 111-121.

Sasikumar, G., Mohamed, K. S., \& Bhat, U. S. (2013). Inter-cohort growth patterns of pharaoh cuttlefish Sepia pharaonis (Sepioidea: Sepiidae) in Eastern Arabian Sea. Revista de Biología Tropical, 61, 01-14.

Schaefer, M. D. (1954). Some aspects of the dynamics of populations important to the management of the commercial marine fishes. Bulletin of Inter-American of Tropical Tuna, 1, 27-56.

Sossoukpe, E., Nunoo, F. K. E., Ofori-Danson, P. K., Fiogbe, E. D., \& Dankwa, J. R. (2013). Growth and mortality parameters of $P$. senegalensis and P. typus (Sciaenidae) in nearshore waters of Benin (West Africa) and their implications for management and conservation. Fisheries Research, 137, 710-720. 
Torrie, R. G. D., Dickey, J. H., \& Steel, D. A. (1996). Principles and Procedures of Statistics ( $3^{\text {rd }}$ ed.). New York: McGraw-Hill.

Von Bertalanffy, L. (1938). A quantitative theory of organic growth. Human Biology, 10, 181-213.

Voss, G. L., \& Solís Ramírez, M. (1966). Octopus maya, a new species from the Bay of Campeche, Mexico. Bulletin of Marine Science, 16, 615-625.

Wahle, C., \& Forgaty, C. (2005). Growth and development: understanding and modelling growth variability in lobsters. In B. Phillips (Ed.), Lobsters: Biology, management, fisheries and aquaculture (pp. 1-44). Oxford, United Kingdom: Blackwell Pub.

Wang, Y. G., \& Milton, D. A. (2000). On comparison of growth curves: How do we test whether growth rates differ? Fishery Bulletin, 98, 874-880.
Whitten, A. R., Klaer, N. L., Tuck, G. N., \& Day, R. W. (2013). Accounting for cohort- specific variable growth in fisheries stock assessments: A case study from south-eastern Australia. Fisheries Research, 142, 27-36.

Wright-López, H., Holguín-Quiñones, O., Arreguín-Sánchez, F., \& Roque-Villada, I. (2009). Crecimiento y mortalidad de la madreperla Pinctada mazatlanica en poblaciones naturales del litoral oriental de Baja California Sur, México. Revista de Biología Tropical, 57, 53-61.

Zar, H. J. (2010). Biostatistical analysis (5 $5^{\text {th }}$ ed.). New York, USA: Prentice-Hall, Englewood Cliffs.

Zetina-Moguel, C. E. \& Ríos-Lara, G. V. (2000). Modelos de crecimiento de langosta (Panulirus argus) y un método para calcular la edad. Ciencia Pesquera, 14, 57-62. 
